\title{
Estágios imaturos de Titaea orsinome Huebner (Lepidoptera, Saturniidae, Arsenurinae)
}

\section{Eurides Furtado $^{1}$}

\begin{abstract}
Immature stages of Titaea orsinome Huebner (Lepidoptera, Saturniidae, Arsenurinae). Data on immature stages, the behavior and the range of Titaea orsinome Huebner, [1823] are presented. The larva feeds on Eriotheca gracilipes (K. Schum.) O. Robyn (Bombacaceae). Generation (oviposition to imago) lasted 77 days. Egg, larval instars, head capsules, pupa and adults are illustrated in color.

KEY WORDS. Saturniidae, Arsenurinae, Titaea orsinome, host plants, immature stages
\end{abstract}

Endemismo da área de vegetação de cerrado do centro oeste brasileiro, Titaea orsinome Huebner, [1823] (Figs 12-13) é espécie tipo do gênero. Das quatro espécies do gênero, T. tamerlan é a única que teve seus estágios imaturos descritos, criada em Chorisia sp. (Bombacaceae) e sua biologia é bastante semelhante a da espécie ora estudada, apesar de suas larvas terem um ínstar a menos (TRAVASSOS \& D'AlMEIDA 1937). Também muito semelhantes são os estágios imaturos de Caio richardsoni (Druce, 1890) (WOLFE \& PESCADOR 1994), Dysdaemonia boreas (Cramer, 1775) (PEIGLER 1993) e Dysdaemonia brasiliensis Rothschild, 1907 (DIAS 1978, como D. boreas).

\section{Morfologia}

\section{Ovo (Fig. 1)}

Elipsóide com as duas faces fortemente achatadas, cório levemente áspero, branco gesso, área central com mancha marrom-escura irregular. Mede: $3,5 \mathrm{~mm}$ no maior eixo e 2,0 no menor. Micrópila preta, na face menor. Período embrionário, 7 dias.

\section{Larva}

Primeiro ínstar (Fig. 2). Cabeça (Fig. 8a) globular, lisa, castanho-avermelhada; frontoclípeo e ocelos escuros. Scoli protorácicos sub-dorsais, castanho-avermelhados; os da área supra-espiracular, pretos. Dois pequenos scoli mesotorácicos pretos com cerdas da mesma cor, nas mesmas áreas que os anteriores. Metatórax com tubérculos sub-dorsais encimados com scoli, tão longos quanto aproximadamente $1 / 3$ do corpo, bifurcados, com uma cerda escura na ponta de cada ramo, castanho-avermelhados, circundados de amarelo pouco abaixo da bifurcação. Todos os segmentos abdominais com pequenos scoli com cerdas pretas, nas mesmas áreas que os do tórax. Dorso de A8 com tubérculo e scolus semelhante mas pouco menor

1) Caixa Postal $97,78400-000$ Diamantino, Mato Grosso, Brasil. 
que os metatorácicos e com o terço apical vermelho, com marmorizações negras. Tegumento: coloração de fundo, castanho-avermelhada; linha negra irregular, interrompida, na área espiracular; coloração amarela com pontos e traços negros, desta área até a sub-dorsal e preta na base dos scoli. Dorso com invasões amarelas, com menor destaque no metatórax e A8. Pernas torácicas avermelhadas; pernas abdominais e anais da mesma coloração do tegumento e com as plantas castanhoescuras. Comprimento da larva ao eclodir, 9,0 mm; no final do ínstar, 15,5 mm. Duração, quatro dias.

Segundo ínstar (Fig. 3). Cabeça (Fig. 8b) com formato e cor como no ínstar anterior; fronte amarela, clípeo castanho-esbranquiçado; área amarelada próximo a base das antenas, estas amareladas na metade basal e castanho-claras na distal; ocelos negros. Protórax com os scoli sub-dorsais grossos, curtos e com ramificações espiniformes. Scoli metatorácicos sub-dorsais, $2 / 5$ do comprimento do corpo, circundados com pequenos espinhos, marrom-escuros, anelados com amarelo na porção ante-mediana e na pós-mediana, porção apical espiniforme e bifurcada. Scolus dorsal de A8 semelhante aos metatorácicos, menor, aproximadamente a metade destes e anelado com amarelo só na porção pós-mediana. Pernas torácicas, abdominais e anais castanho-avermelhadas. Area ventral castanho-avermelhada nos segmentos torácicos e em A 1-2 e amarelada nos demais. Tegumento amarelo, com pontuação castanho-escura e invasões ferrugíneas, da área sub-ventral à sub-espiracular: nos segmentos torácicos; em A4-5 e A7-10; na área supra-espiracular em A1-3 e A6; na área dorsal do protórax; em pequena porção dorsal do mesotórax; na maior parte dos tubérculos do metatórax e em A8; na metade dorsal de A1; em quase todo dorso de A2-3 e A7; pouco menos em A8-9 e bem menos em A6. Placa supranal e escudos das pernas anais, castanho-avermelhadas com invasões amarelas. Espiráculos castanhos, com o peritrema castanho-escuro, circundados com coloração ferrugínea, exceto em A3-4. Comprimento, 22,5 mm. Duração, sete dias.

Terceiro ínstar (Fig. 4). Cabeça (Fig. 8c) mais escura, sobretudo na área frontal. Scoli torácicos e de A8, marrom-escuros. Pernas torácicas e abdominais castanho-escuras. Tegumento amarelo, com pontos castanho-escuros e invasões escuras assim distribuídas: castanho-escura, orlada com coloração mais escura no dorso do protórax; em pequena porção dorsal de T2; na base dos scoli de T3, A1 e A6-7; na base do scolus de A8; porção dorsal maior entre A2-3; da sub-ventral à supra-espiracular na metade posterior de $\mathrm{A} 2 \mathrm{e}$ em $\mathrm{A} 3$ até a área supra-espiracular e parte central de A6. Dorso alaranjado em A4-5 e metade de A6 e castanho em A9-10. Espiráculos com peritrema ferrugíneo e dois pontos esbranquiçados, um ventral e outro dorsal. Cerdas esbranquiçadas nas pernas torácicas e abdominais. Tonalidade esverdeada com marmorizações castanhas, da área ventral de $\mathrm{A} 4$ à placa supranal e na planta das pernas abdominais e anais. Comprimento, $30,0 \mathrm{~mm}$. Duração, quatro dias.

Quarto ínstar (Fig. 5). Cabeça (Fig. 8d) verde-oliva, demais detalhes como no instar anterior. Scoli protorácicos com os espinhos menores que antes e coloração mais clara; os metatorácicos como no ínstar anterior, mas com a área amarela maior. Área dorsal de T1 com traço e de T2 com grande ponto castanho-escuros. Vaso dorsal amarelado, com mais destaque de A3 a A6. Scolus dorsal de A8 amarelo na 

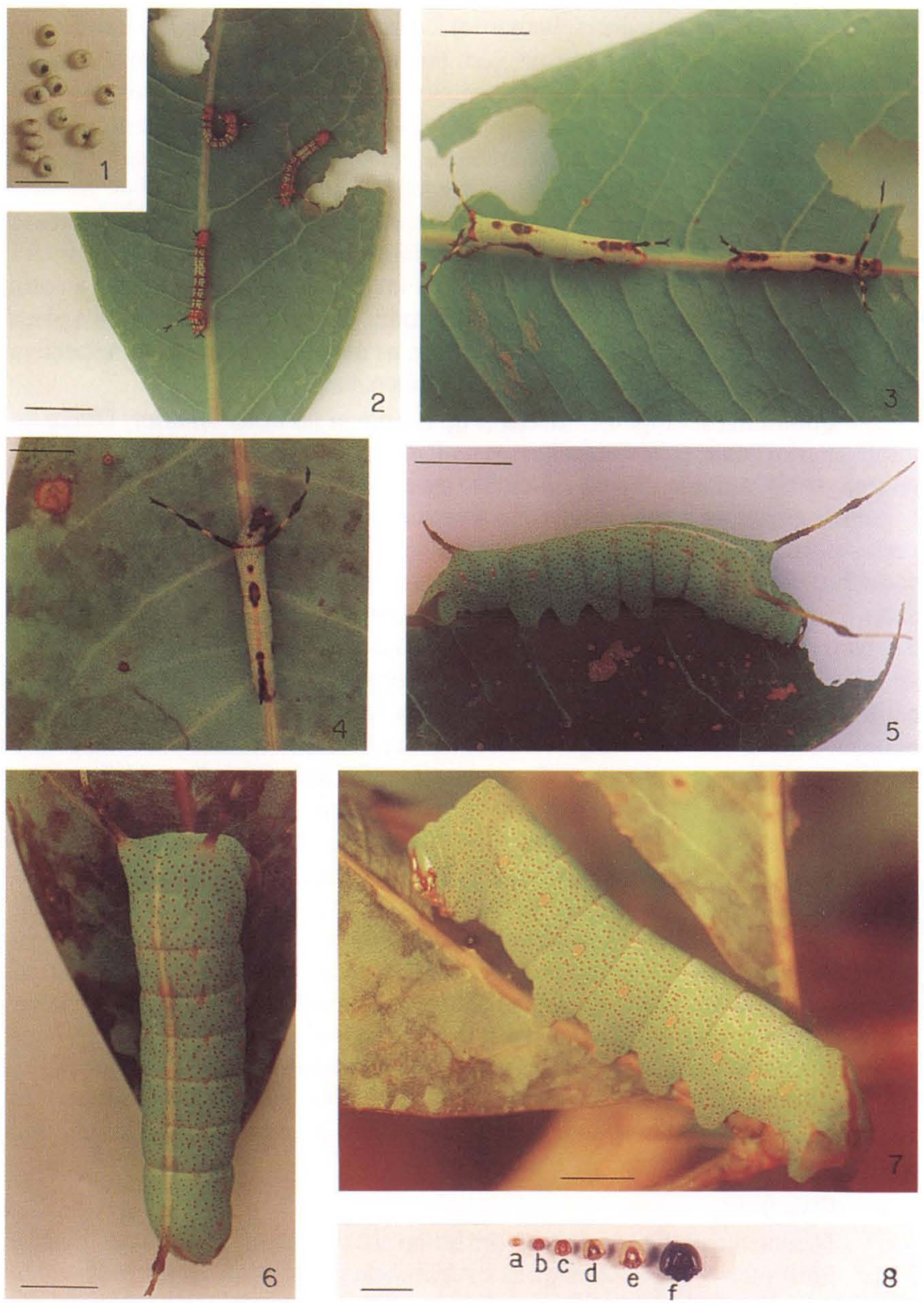

Figs 1-8. Titaea orsinome. (1) Ovos; (2-7) larvas de: (2) primeiro instar, vista dorsal; (3) segundo instar, vista dorsal; (4) terceiro ínstar, vista dorsal; (5) quarto ínstar, vista laterodorsal; (6) quinto ínstar, vista dorsal; (7) larva de sexto instar, vista lateral; (8) vista frontal das cápsulas cefálicas: (a) primeiro instar, (b) segundo instar, (c) terceiro ínstar, (d) quarto ínstar, (e) quinto instar, (f) sexto instar (com a coloração alterada). 
porção ante- e na pós-mediana. Pernas torácicas, abdominais e anais parcialmente castanhas. Tegumento verde-citrino, com pontuação e manchas ferrugíneas assim distribuídas: manchas irregulares sub-ventrais em A1-2 e A5-6; mancha trapezoidal na área espiracular, iniciada no terço posterior de $\mathrm{A} 2$ até o meio de $\mathrm{A} 3$ e orlada com coloração mais escura; mancha arredondada, também com orla mais escura, na área espiracular de A6; pequenas manchas irregulares sub-dorsais em A1-4; mancha ovalada dorsal da metade de $\mathrm{A} 2$ ao terço de $\mathrm{A} 3$; manchas em forma de dois pequenos traços, uma em cada lado do vaso dorsal no limites de A1 com A2, de A3 com A4 e de A5 com A6; mancha ovalada dorsal do meio de A6 ao terço de A7 e outra menor daí ao limite com A8. Área dorsal castanha, do terço posterior de A8 à placa supranal. Espiráculos como no ínstar anterior, os de A3 e A6 dentro da respectiva mancha. Comprimento, 39,5 mm. Duração, cinco dias.

Quinto ínstar (Fig. 6). Cabeça (Fig. 8e) como no ínstar anterior. Difere do ínstar anterior nos seguintes detalhes: os scoli metatorácicos são verde-oliva-escuros no terço basal, seguido de amarelo-citrino até a nodulação, esta da mesma cor basal e a seguir amarelo-citrino até próximo ao ápice, este castanho; scolus dorsal de A8 verde-oliva da base à nodulação e em seguida um pouco mais claro, com o ápice castanho; pernas torácicas verde-oliva-escuras; escudos das pernas abdominais e anais e escudo supranal castanho-esverdeados com cerdas esbranquiçadas; planta das pernas abdominais e anais, castanhas; vaso dorsal esbranquiçado e mais largo de A1 a A8 e vináceo com margens esbranquiçadas em A9-10; espiráculos com peritrema castanho, esbranquiçados nas áreas basal e dorsal; tegumento verde, pouco mais claro na área dorsal e ventral, com pontuação castanho-escura, orlada com coloração verde mais clara. Comprimento, $56,0 \mathrm{~mm}$. Duração, seis dias.

Sexto ínstar (Fig. 7). Cabeça (Fig. 8f) verde-oliva, com áreas castanho-escuras limítrofes ao epicrânio e suas suturas e na área ocelar; fronte branca com invasões castanho-escuras em todos os lados; frontoclípeo verde-amarelado; mandíbulas castanho-escuras com os bordos cortantes pretos; antenas esbranquiçadas na metade basal e castanhas na terminal. Metatórax e A8 mais volumosos, corcovados e sem os scoli. Pernas torácicas castanhas com cerdas esbranquiçadas; pernas abdominais e anais como no ínstar anterior. Tegumento semelhante ao ínstar anterior, mas com a pontuação mais fina e mais escura no protórax, da área supra-espiracular ao dorso e com cinco pequenas manchas sub-dorsais, de A2-6, esbranquiçadas com reflexos violáceos, cada uma localizada na borda anterior do segmento, as duas últimas com menor nitidez que as demais, todas no mesmo alinhamento. Comprimento, $85,0 \mathrm{~mm}$. Duração, 11 dias.

\section{Pupa (Figs 9-11)}

Tegumento castanho-escuro, com brilho nos segmentos abdominais. Vértice e áreas limítrofes com protuberâncias e rugosidade grosseira. Área laterodorsal do tórax com rugosidade fina. Antenas com pequenas protuberâncias lisas longitudinais. Peças bucais, pernas e estojo das asas com granulação fina. Espaços intersegmentais fortemente sulcados. Espiráculos elipsoidais; área periférica com granulação forte. Cremaster hastado, longo, com protuberâncias lisas laterais e dorsais e fortemente sulcado na área ventral. Comprimento, 50,0 mm; largura maior, 17,2 $\mathrm{mm}$; largura menor, $17,0 \mathrm{~mm}$. Período pupal, 33 dias. 

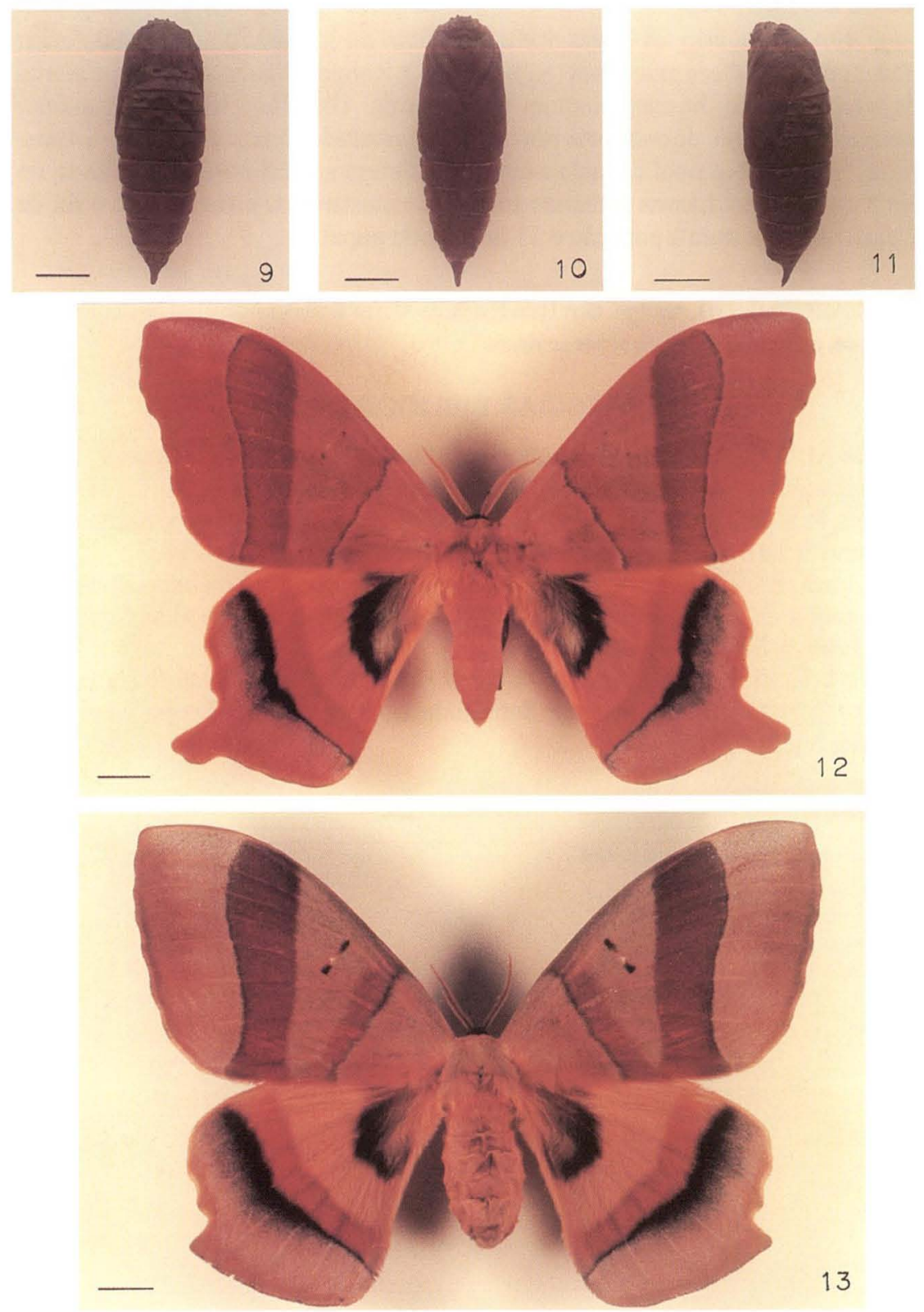

Figs 9-13. Titaea orsinome. (9-11) Pupa: (9) vista dorsal; (10) vista ventral; (11) vista lateral; (12) macho, vista dorsal; (13) fêmea, vista dorsal. Escala $=10 \mathrm{~mm}$. 


\section{Dados bionômicos}

Em laboratório, as larvas aceitaram Chorisia speciosa St. Hil., mas foram criadas com Eriotheca gracilipes (K. Schum.) O. Robyn (Bombacaceae), sua planta hospedeira natural, bastante comum na região do Alto Rio Arinos, Diamantino, Mato Grosso, Brasil, de onde procede o material estudado. A postura da fêmea mater foi de 234 ovos. No final do ciclo a larva empalidece sua coloração, e oculta-se no solo para pupação. Larvas solitárias em todos os ínstares. O ciclo evolutivo foi de 77 dias, 44 da postura à pupação e 33 de período pupal.

AGRADECIMENTO. Ao Prof. Gert Hatschbach, do Museu Botânico Municipal de Curitiba, Paraná, pela identificação da planta nutridora.

\section{REFERÊNCIAS BIBLIOGRÁFICAS}

DIAS, M.M. 1978. Morfologia e biologia de Dysdaemonia boreas (Cramer, 1775) (Lepidoptera, Adelocephalidae). Revta bras. Ent., São Paulo, 22 (2): 83-90. PEIGLER, R.S. 1993. Cladisc Analysis of the Genera of the Subfamily Arsenurinae (Saturniidae). Jour. Lepidop. Soc., Los Angeles, 47 (3): 211-228.

Travassos, L. \& R.F. D'AlmEIDA. 1937. Contribuição para o conhecimento da bionomia de alguns lepidopteros brasileiros. Mem. Inst. Oswaldo Cruz, Rio de Janeiro, 32 (4): 499-503.

Wolfe, K.L. \& A. PESCADOR. 1994. Caio richardsoni: its immature stages and natural history (Lepidoptera: Saturniidae: Arsenurinae). Trop. Lepidop., Gainesville, 5 (1): 29-32.

Recebido em 10.XII.1998; aceito em 16.XI.1999. 